\title{
Mobilidade versus ciclismo: análise da viabilidade do modal cicloviário no contexto urbano da cidade de Porto Nacional
}

Discorrer sobre a mobilidade urbana certamente contribuirá para melhoria de locomoção nas cidades, com ou acima de vinte mil habitantes, com o intuito de estimular e possibilitar uma maior locomoção através de veículos não motorizados. Desta maneira, este estudo teve como objetivo geral mapear a área escolhida para a implantação da ciclovia em Porto Nacional, visando à mobilidade urbana. Os objetivos específicos foram: levantar a opinião da população no que diz respeito à importância do Plano de Mobilidade Urbana, bem como a satisfação deles quanto os itens de acessibilidade, segurança e sinalização viária de Porto Nacional. A metodologia utilizada foi pesquisa de campo descritiva, sendo que a amostra foi composta por 400 pessoas residentes na cidade de Porto Nacional. Os resultados da pesquisa demonstraram que a população se encontra insatisfeita com a acessibilidade, conservação das ruas, sinalização viária e segurança viária, porém, demonstraram satisfação com a implantação de uma malha cicloviária no município. Ao final, concluiu-se que a população de Porto Nacional considera importante um bom plano de mobilidade urbana uma vez que induz a uma maior qualidade nos deslocamentos entre bairros e centralidades.

Palavras-chave: Ciclovia; Mobilidade Urbana; Acessibilidade.

\section{Mobility versus cycling: analysis of the viability of the cycling modal in the urban context of Porto Nacional}

Talking about urban mobility will certainly contribute to the improvement of mobility in cities with or above twenty thousand inhabitants, in order to stimulate and enable greater mobility through non-motorized vehicles. Thus, this study aimed to map the area chosen for the implementation of the bicycle path in Porto Nacional, aiming at urban mobility. The specific objectives were: to raise the opinion of the population regarding the importance of the Urban Mobility Plan, as well as their satisfaction regarding the accessibility, safety and road signs of Porto Nacional. The methodology used was a descriptive field research, and the sample consisted of 400 people living in the city of Porto Nacional. The survey results showed that the population is dissatisfied with accessibility, street conservation, road signs and road safety, however, showed satisfaction with the implementation of a cycling network in the municipality. In the end, it was concluded that the population of Porto Nacional considers a good urban mobility plan to be important as it induces a higher quality of travel between neighborhoods and centralities.

Keywords: Bicycle path; Urban mobility; Accessibility.

\section{Topic: Engenharia Urbana}

Reviewed anonymously in the process of blind peer.
Received: 19/04/2019

Approved: $21 / 07 / 2019$
Angella Augusta Alves de Oliveira

Instituto Tocantinense Presidente Antônio Carlos, Brasil http://lattes.cnpq.br/8531112099162758 angella_rufino@outlook.com

José Djair Casado de Assis Junior

Instituto Tocantinense Presidente Antônio Carlos, Brasil

http://lattes.cnpq.br/4023545131498764

djairjunior@gmail.com
Referencing this:

OLIVEIRA, A. A. A.; ASSIS JUNIOR, J. D. C.. Mobilidade versus ciclismo: análise da viabilidade do modal cicloviário no contexto urbano da cidade de Porto Nacional. Engineering Sciences, v.7, n.2, p.86-93, 2019. DOI: http://doi.org/10.6008/CBPC2318-3055.2019.002.0010 


\section{INTRODUÇÃO}

São cada vez maiores as exigências por mobilidade urbana, e este tema vem ganhando espaço em todo o cenário nacional. Isto talvez se justifica devido ao rápido crescimento urbano, sendo que este não foi acompanhado, na mesma velocidade, pelos investimentos de infraestrutura que são necessários para se dispor de uma boa mobilidade, o que tem provocado congestionamentos de trânsito nas grandes cidades, bem como tem ocasionado o desgaste das condições dos serviços públicos (VIANNA, 2013).

Outro fator importante diz respeito ao crescimento da população urbana, que tem como consequência um aumento da necessidade por mobilidade, e por este motivo alguns aspectos acabam sendo influenciados diretamente, como é o caso da infraestrutura urbana e das questões de mobilidade, que se consistem no aumento de carros, transporte coletivo insuficiente, trânsito obstruído, dentre outros (IPPLAN, 2016).

E para satisfazer esta demanda não é possível somente crescer em infraestrutura, havendo necessidade de se implantar estratégias que reduzam a demanda, e por este motivo é importante que se invistam em transportes alternativos, como é o caso da construção de ciclovias, por serem as mesmas uma alternativa que vai além do lazer, além de ser um importante equipamento público que incentiva a utilização da bicicleta como meio de transporte (COLPANI et al., 2015). Neste sentido, o Programa Brasileiro de Acessibilidade Urbana, destaca que o transporte urbano é um serviço público necessário para boa utilização da cidade e suas ofertas, sendo que ele deve considerar

[...] Diminuir o número de viagens motorizadas; repensar o desenho urbano; repensar a circulação de veículos; reconhecer a importância do deslocamento dos pedestres; proporcionar mobilidade às pessoas com deficiência e restrição de mobilidade nos meios de transportes e locomoção; priorizar o transporte coletivo.

Os órgãos públicos, responsáveis pelas políticas públicas relacionadas ao trânsito, possuem como foco implementar recursos que contribuam para que a mobilidade realmente funcione e de maneira sustentável. E neste âmbito, a bicicleta é o meio de transporte que melhor cumpre esse papel (SOARES, 2015). A bicicleta é um veículo individual não motorizado mais usado nas pequenas cidades brasileiras (cidades com menos de 60 mil habitantes) e em países europeus como Holanda, Alemanha e Dinamarca que possuem larga tradição no uso da bicicleta. Utilizada para ir até a escola, emprego, atividades de lazer, exercício físico, para carteiros nas entregas domiciliares, e pequenos comércios que faz entrega de água mineral ou compras usando a bicicleta (LORDELLO, 2012).

Conforme afirma Czerwonka (2016), muitas cidades têm investido em ciclovias em todo o mundo, sendo que este investimento talvez se explique devido as bicicletas serem um meio de transporte completo, além de ajudarem a reduzir o trânsito nas grandes metrópoles, as bikes são, ainda, um meio de transporte ecológico. Segundo Lordello (2012), a bicicleta se manifesta como parte da solução para atender às demandas por mobilidade e transporte nas cidades. Além de cumprir um papel importante como mercadoria que contribui para o crescimento econômico, ela tem um grande potencial de servir de suporte como meio de transporte. 
Sendo assim, esta pesquisa justifica-se pela necessidade de buscar alternativas para a mobilidade através do uso de veículos não motorizados, como é o caso do ciclismo que surge como alternativa para minimizar os malefícios provocados ao meio ambiente causados pela grande utilização de transportes automotores. Em meio a este cenário, a bicicleta surge como uma ótima alternativa para desafogar o trânsito das cidades.

O objetivo geral da pesquisa pautou-se em: mapear a área escolhida para a implantação da ciclovia em Porto Nacional, visando à mobilidade urbana. Os objetivos específicos foram: levantar a opinião da população no que diz respeito à importância do Plano de Mobilidade Urbana, bem como a satisfação deles quanto os itens de acessibilidade, segurança e sinalização viária de Porto Nacional.

\section{METODOLOGIA}

Desenvolveu-se uma pesquisa de campo descritiva que buscou informações sobre a qualidade da mobilidade urbana no município de Porto Nacional, estado do Tocantins, buscando minimizar os problemas relacionados ao trânsito, e por consequência à mobilidade urbana. Através da pesquisa observou-se que quando se pretende construir uma ciclofaixa é necessário aplicar, de modo exclusivo, algumas normas e especificidades, assim como quando se constrói estradas, ruas avenidas e rodovias. $\mathrm{O}$ transporte que foi foco desta pesquisa foi a bicicleta e por este motivo foi necessário analisar os vários modelos de ciclofaixa, devido os padrões de bicicleta existentes, conforme demonstra a figura 1

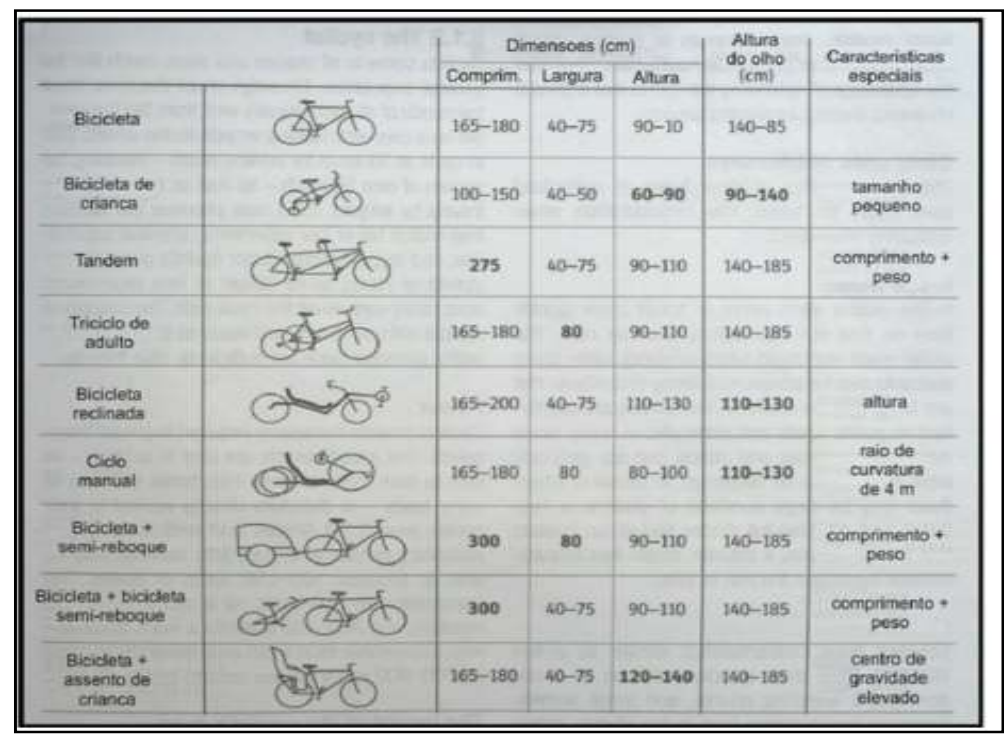

Figura 1: Tipos de bicicletas existentes. Fonte: Alves et al. (2012).

Na busca de adquirir informações sobre a opinião da população no que diz respeito à importância do Plano de Mobilidade Urbana, bem como a satisfação dos mesmos quanto os itens de acessibilidade, segurança e sinalização viária de Porto Nacional, estado do Tocantins, aplicou-se um questionário a uma amostra de 400 (quatrocentas) pessoas. Para se chegar a esta amostragem, utilizou-se como parâmetro a fórmula estabelecida por Martins et al. (2014), que é $n=Z^{2} \infty / 2$.p.q. $N / d^{2}(N-1)+Z 2 \infty / 2$.p.q, onde: $n=$ tamanho

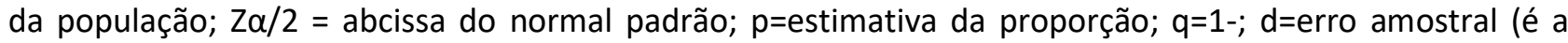


máxima diferença que o investigador admite suportar entre um resultado amostral e o verdadeiro resultado populacional); e $\mathrm{N}=$ tamanho da amostra aleatória simples a ser selecionada da população.

Para calcular o tamanho da amostra desta pesquisa, admitiu-se um nível de confiança de $95 \%$, um erro amostral de 5\%, p=0,50 e q=1-. Considerando a população em estudo e utilizando a equação e os dados acima, foram obtidos os seguintes resultados: $\mathrm{n}=1,96^{2} .0,50.0,50.52828 / 0,05^{2}(52510-1)+1,96.0,50.0,50$; $n=382,73 ; n \cong 400$.

\section{RESULTADOS E DISCUSSÃO}

Porto Nacional é um município que possui, segundo dados do IBGE, uma população de 52.700 habitantes. É um município que não dispõe de adequação do sistema viário, e por este motivo, é importante o planejamento de um sistema cicloviário, a fim de dar mobilidade aos usuários. No município, a maioria dos usuários que utilizam a bicicleta para seus deslocamentos ao trabalho, fazem de maneira perigosa, sendo que o destino principal de trabalho está concentrado na área central da cidade.

Ao mapear a área escolhida para a realização da ciclovia em Porto Nacional, percebeu-se que ela pode garantir uma alternativa de deslocamento à população, democratizando o transporte de forma socialmente inclusiva, desafogando o trânsito em horário de pico. O mapeamento da área escolhida está demonstrado na figura 2 .

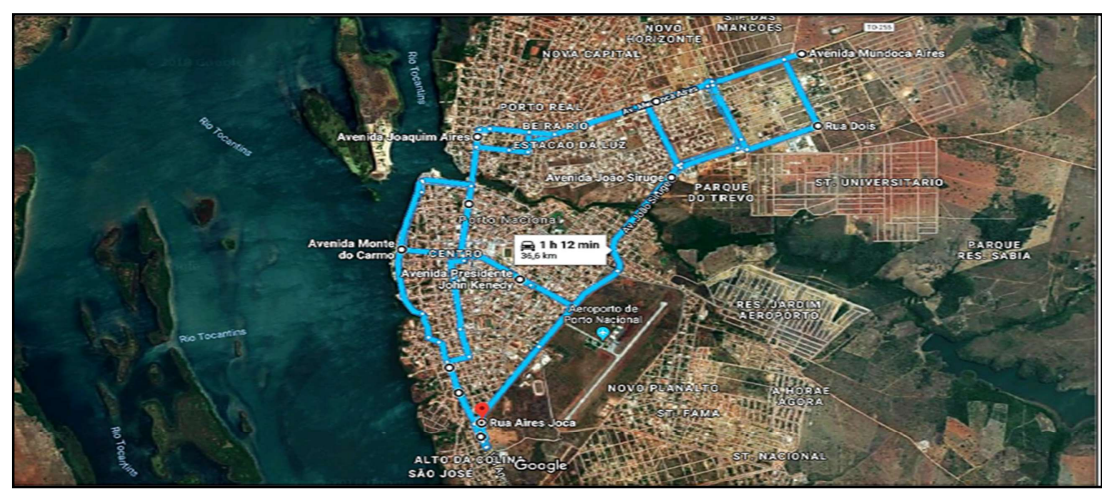

Figura 2: Mapeamento da área escolhida para implantação de ciclovias na cidade de Porto Nacional (TO).

Após a realização do mapeamento da área adequada para a implantação de um projeto cicloviário em Porto Nacional, buscou-se conhecer a opinião da população no que diz respeito à importância do Plano de Mobilidade Urbana, bem como a satisfação dos mesmos quanto os itens de acessibilidade, segurança e sinalização viária de Porto Nacional, por meio da aplicação de um questionário. Foram pesquisadas 400 pessoas aleatoriamente. Buscou-se identificar qual era o bairro de moradia do entrevistado, sendo que as respostas obtidas estão descritas na tabela abaixo. Logo após, buscou-se identificar o sexo, idade, estado civil, classe social e escolaridade das pessoas entrevistadas, conforme demonstrado na tabela 2.

Logo após, buscou-se identificar alguns indicadores, ligando-os ao grau de importância/satisfação, conforme demonstrado no gráfico 1 . O bairro que trabalho, a frequência de viagens, o meio de transporte e o tempo gasto com o deslocamento da origem até o local de trabalho, foram outras variáveis analisadas, conforme segue descrito abaixo. 
Tabela 1: Descrição da população segundo o bairro de moradia.

\begin{tabular}{|c|c|c|}
\hline BAIRRO & $\mathbf{N}$ & $\%$ \\
\hline Aeroporto & 31 & 8 \\
\hline Jardim Brasília & 26 & 7 \\
\hline Nova Capital & 20 & 5 \\
\hline Vila Nova & 27 & 7 \\
\hline Jardim América & 15 & 4 \\
\hline Centro & 33 & 9 \\
\hline Cruzeiro do Sul & 25 & 7 \\
\hline Alto da Colina & 30 & 8 \\
\hline Santa Helena & 25 & 7 \\
\hline Jardim Querido & 29 & 8 \\
\hline Jardim Municipal & 28 & 8 \\
\hline Umuarama & 30 & 8 \\
\hline Vila Operária & 25 & 7 \\
\hline Novo Planalto & 10 & 3 \\
\hline Porto Real & 15 & 4 \\
\hline Setor Nacional & 14 & 4 \\
\hline Parque da Liberdade & 17 & 3 \\
\hline
\end{tabular}

Tabela 2: Caracterização da população conforme sexo, idade, estado civil, classe social, escolaridade.

\begin{tabular}{|c|c|c|}
\hline DESCRIÇÃO & $\mathbf{N}$ & $\%$ \\
\hline \multicolumn{3}{|l|}{ Sexo } \\
\hline Masculino & 299 & 72 \\
\hline Feminino & 101 & 28 \\
\hline \multicolumn{3}{|l|}{ Idade } \\
\hline De 14 a 18 anos & 33 & 8 \\
\hline De 19 a 30 anos & 135 & 34 \\
\hline De 31 a 50 anos & 204 & 51 \\
\hline Acima de 51 anos & 28 & 7 \\
\hline \multicolumn{3}{|l|}{ Estado Civil } \\
\hline Casado & 148 & 26 \\
\hline Solteiro & 199 & 34 \\
\hline Viúvo & 10 & 2 \\
\hline Separado & 31 & 8 \\
\hline União Estável & 12 & 3 \\
\hline \multicolumn{3}{|l|}{ Classe Social } \\
\hline Baixa & 82 & 21 \\
\hline Média & 305 & 77 \\
\hline Alta & 13 & 3 \\
\hline \multicolumn{3}{|l|}{ Escolaridade } \\
\hline Analfabeto & 12 & 3 \\
\hline Ensino Fundamental Incompleto & 21 & 5 \\
\hline Ensino Fundamental Completo & 28 & 7 \\
\hline Ensino Médio Incompleto & 34 & 7 \\
\hline Ensino Médio Completo & 180 & 8 \\
\hline Ensino Superior Incompleto & 102 & 45 \\
\hline Ensino Superior Completo & 23 & 26 \\
\hline
\end{tabular}

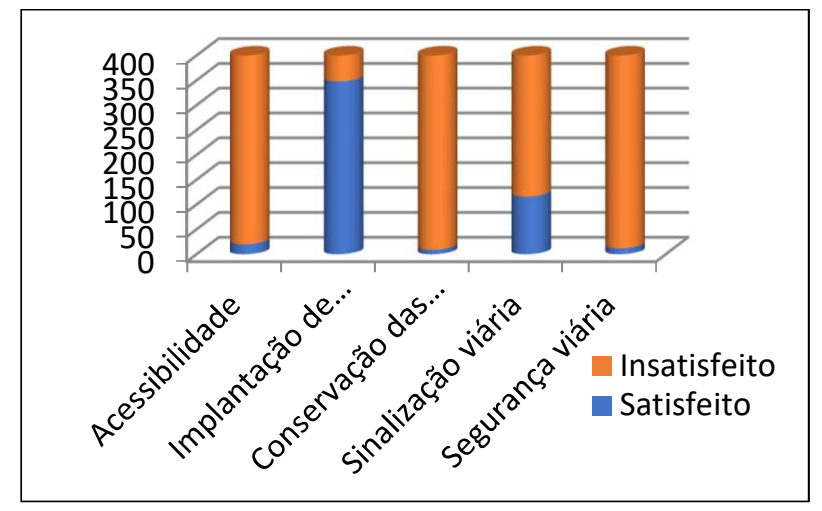

Gráfico 1: Demonstração do grau de importância/satisfação com indicadores de acessibilidade, sistema viário, conservação das ruas, sinalização viária e segurança viária. 
Tabela 3: Demonstração dos resultados conforme o bairro em que trabalha, a frequência de viagens, o meio de transporte e o tempo gasto com o deslocamento da origem até o local de trabalho.

\begin{tabular}{|c|c|c|}
\hline DESCRIÇÃO & $\mathbf{N}$ & $\%$ \\
\hline \multicolumn{3}{|l|}{ Local de Trabalho } \\
\hline Jardim Brasília & 24 & 6 \\
\hline Ypê & 35 & 9 \\
\hline Setor Aeroporto & 88 & 22 \\
\hline Centro & 207 & 52 \\
\hline Vila Militar & 10 & 2 \\
\hline Jardim América & 08 & 2 \\
\hline Porto Real & 12 & 3 \\
\hline Novo Planalto & 16 & 4 \\
\hline \multicolumn{3}{|l|}{ Frequência de Viagens } \\
\hline 1 & 10 & 2 \\
\hline 2 & 248 & 62 \\
\hline 3 & 0 & 0 \\
\hline Mais de 3 & 142 & 36 \\
\hline \multicolumn{3}{|l|}{ Meio de Transporte } \\
\hline Carro & 130 & 32 \\
\hline Moto & 180 & 45 \\
\hline Bicicleta & 88 & 22 \\
\hline A pé & 02 & 1 \\
\hline \multicolumn{3}{|l|}{ Tempo gasto com o transporte } \\
\hline 0 a 20 minutos & 267 & 67 \\
\hline 21 a 40 minutos & 123 & 31 \\
\hline 1 hora ou mais & 10 & 2 \\
\hline
\end{tabular}

Buscou-se identificar se a pessoa pesquisada estaria disposta a trocar seu veículo por uma ciclovia, bem como buscou-se identificar se ele utilizasse a ciclovia quanto tempo poderia gastar para se locomover até o seu trabalho. As respostas estão demonstradas na tabela 4, denominada 'Demonstração dos resultados da pesquisa quanto a intenção da população em trocar seu veículo por uma ciclovia e identificação do tempo gasto se ele utilizasse a ciclovia'. Para finalizar, buscou-se identificar se caso a ciclovia fosse implantada, qual seria o grau de importância dela, segundo a segurança, conforto, acessibilidade e agilidade, sendo que as respostas estão demonstradas no gráfico abaixo.

Tabela 4: Demonstração dos resultados da pesquisa quanto a intenção da população em trocar seu veículo por uma ciclovia e identificação do tempo gasto se ele utilizasse a ciclovia.

\begin{tabular}{|l|c|c|}
\hline \multicolumn{1}{|c|}{ DESCRIÇÃO } & N & \% \\
\hline Intenção trocar veículo por ciclovia & 114 & 29 \\
\hline Sim & 89 & 22 \\
\hline Não & 197 & 49 \\
\hline Talvez & \multicolumn{2}{|c|}{} \\
\hline Quanto tempo gastaria se utilizasse a ciclovia & 228 & 57 \\
\hline 0 a 20 minutos & 157 & 39 \\
\hline 21 a 40 minutos & 15 & 4 \\
\hline 1 hora ou mais & \multicolumn{2}{|c|}{} \\
\hline
\end{tabular}

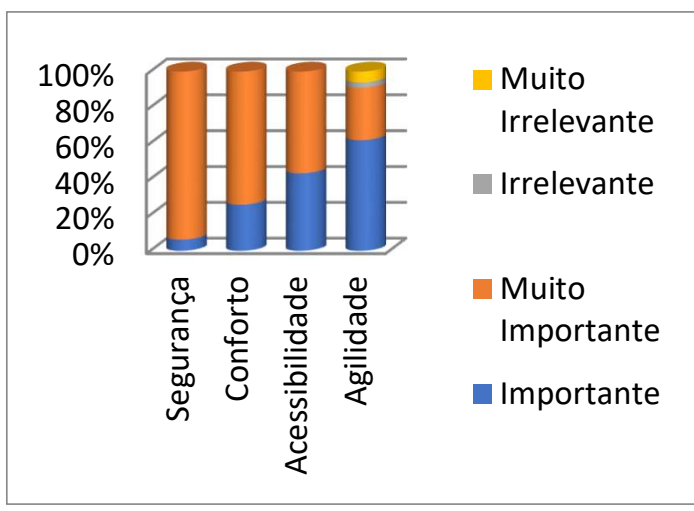

Gráfico 2: Demonstração do grau de importância/satisfação com indicadores de acessibilidade, sistema viário, conservação das ruas, sinalização viária e segurança viária. 
A primeira fase deste trabalho pautou-se em realizar um mapeamento da área escolhida para implantação de ciclovias na cidade de Porto Nacional (TO). Ao se analisar o que foi proposto para a cidade, percebe-se que a estrutura sugerida é capaz de garantir uma alternativa de deslocamento à população, democratizando o transporte de forma socialmente inclusiva, desafogando o trânsito em horário de maiores picos.

A este respeito, Colpani et al. (2015) a implantação de ciclovias é uma das alternativas que mais deve contribuir para a vida das pessoas, uma vez que o transporte é uma atividade essencial para todas as classes sociais e o uso da bicicleta nos deslocamentos caracteriza esta concepção, independente do poder aquisitivo, a bicicleta é um veículo não motorizado mais acessível.

Dallazen (2018) complementa afirmando que as ciclovias, vias para ciclistas separadas do tráfego geral, podem acompanhar paralelamente o sistema viário geral ou de maneira independente. São separadas fisicamente das faixas designadas ao transporte motorizado por um meio-fio ou canteiro, que só é descartado em raras intersecções. Por ser segregada, é considerada a via que exibe o maior nível de segurança e conforto aos ciclistas.

Logo após esse planejamento, realizou-se uma entrevista com a população de Porto Nacional, para levantar diversas variáveis que se considera importantes para se analisar a viabilidade do modal cicloviário no contexto urbano de Porto Nacional. Verificou-se que a amostra coletada é distribuída em diversos grupos distintos divididos em sexo, faixa etária, renda e escolaridade. Em relação a variável sexo, percebeu-se que a grande maioria (72\%) era do sexo masculino. A faixa etária teve participação significativa de pessoas adultas, representando $51 \%$ da amostra com idade entre 31 a 50 anos. Tal fato pode ser explicado devido à presença desse público em locais comerciais e em locais específicos de coleta da amostra, como é o caso da avenida beira rio.

Sobre a escolaridade, prevaleceu os indivíduos com superior incompleto, com $45 \%$ da amostra. A grande parcela de pessoas ingressas nessa última fase de ensino pode ser justificada pelo fato em que a maioria dos locais de coleta são regiões centralizadas. Verificou-se que a amostra demonstra satisfação com a ideia de implantação de um sistema cicloviário no município.

Esta satisfação positiva para a implantação da ciclovia pode ser explicada, uma vez que deslocar é uma necessidade do ser humano. Porém, nos centros urbanos, tal prática é um desafio para o dia a dia. Sendo assim, a principal estratégia para melhorar a qualidade de vida das pessoas passa a ser a otimização do sistema de transportes públicos, além do incentivo aos modos individuais não motorizados. O que se tem percebido é que existe uma urgência em se criar meios para um equilíbrio entre transporte, habitação, circulação de carros e pedestres e a manutenção de áreas verdes (SILVA, 2012).

Outro ponto importante identificado na pesquisa foi a de que $49 \%$ da amostra afirma que talvez trocaria seu veículo por uma ciclovia e $29 \%$ afirmam categoricamente que, sim, que trocariam seu veículo para utilizar uma ciclovia. Neste quesito é importante destacar que a falta de segurança pública é o item que mais restringe a substituição de um veículo ou moto por uma bicicleta, ou por um transporte púbico e até mesmo por um percurso a pé. $\mathrm{O}$ que se tem presenciado é que pedestres e ciclistas dão preferência por 
trafegar arriscadamente por grandes avenidas, em meio a alta velocidade dos veículos para evitar as vias mais tranquilas, como é o caso das ciclovias, devido elas estarem mais vulneráveis à violência, como por exemplo, a assaltos.

A visão da amostra quanto a importância da implantação da ciclovia, pensando em segurança, conforto, acessibilidade e agilidade foi algo que demonstrou que as pessoas possuem uma boa ideia sobre a ciclovia. Sendo assim é importante que se analise a viabilidade deste modelo de locomoção, uma vez que para a implantação de uma ciclovia é necessário que se promova uma malha cicloviária eficiente ao sistema de mobilidade urbana da cidade, para poder proporcionar continuidade em seu traçado, garantindo a segurança física do ciclista, construindo os espaços cicláveis separadamente das ruas e com sinalização apropriada (ALMEIDA, 2017).

\section{CONCLUSÃO}

Neste trabalho, realizou-se um mapeamento de uma área para implantação da ciclovia na cidade de Porto Nacional. Verificou-se que a mobilidade induz a uma maior qualidade nos deslocamentos entre bairros e centralidades, e por este motivo é uma ferramenta essencial para a promoção da infraestrutura. Verificouse que a população de Porto Nacional considera importante um bom plano de mobilidade urbana. Porém, demonstraram insatisfeitos com a acessibilidade urbana, conservação das ruas, sinalização viária e segurança viária. Quanto à implantação de um sistema cicloviário, a população demonstrou satisfação com a ideia proposta nesta pesquisa. Para finalizar, sugere-se que os gestores públicos se atentem para a importância da implantação de uma malha cicloviária para o município de Porto Nacional, uma vez que a população se mostrou satisfeita com a ideia desta implantação.

\section{REFERÊNCIAS}

ALMEIDA, J. F. A.. Mobilidade ativa: repensando o uso do espaço urbano e deslocamentos na área central do bairro de Santa Cruz/RJ. Monografia (Graduação) - Universidade Federal Rural do Rio de Janeiro, Seropédica, 2017.

BRASIL. Ministério das Cidades. Programa Brasileiro de Acessibilidade Urbana: Brasil Acessível. Brasília: MC, 2006.

COLPANI, E.; BALDISSERA, A. D.. Implantação de ciclovias: Chapecó como uma cidade sustentável. Revista Tecnológica, v.3, n.2, p.154-173, 2015.

CZERWONKA, M.. Benefícios da bicicleta para a saúde. Curitiba: 2016.

DALLAZEN, J. B.. Segurança nas ciclovias para os usuários no município de Cascavel-PR. In: SIMPÓSIO DE SUSTENTABILIDADE E CONTEMPORANEIDADE NAS CIÊNCIAS SOCIAIS, 6. Anais. Cascavel: 2018.

IPPLAN. Instituto de Pesquisa e Planejamento. Construindo o futuro das cidades para as pessoas: Relatório final da mobilidade urbana. Diagnóstico e prognóstico. Tremembé: IPPLAN, 2016.

LORDELLO, L. P.. A contribuição das políticas de estímulo ao uso da bicicleta para o desenvolvimento da mobilidade sustentável nas cidades. Monografia (Graduação) Universidade Federal do Paraná, Curitiba, 2012

SILVA, A. H. L.. Estimativa de proporções em questões poliatômicas. Revista do TCU, p.18-27, 2012.

SOARES, R. D. G.. Bicicleta e mobilidade urbana: modismo ou solução sustentável para o transporte na cidade de São Paulo. Monografia (Graduação) - Universidade de São Paulo, São Paulo, 2015.

VIANNA, G. S. B.. Mobilidade urbana no Brasil: uma estimativa do produto perdido em trânsito. Monografia (Graduação) - Universidade Federal do Rio de Janeiro, Rio de Janeiro, 2013.

A CBPC - Companhia Brasileira de Produção Científica (CNPJ: 11.221.422/0001-03) detém os direitos materiais desta publicação. Os direitos referem-se à publicação do trabalho em qualquer parte do mundo, incluindo os direitos às renovações, expansões e disseminações da contribuição, bem como outros direitos subsidiários. Todos os trabalhos publicados eletronicamente poderão posteriormente ser publicados em coletâneas impressas sob coordenação da Sustenere Publishing, da Companhia Brasileira de Produção Científica e seus parceiros autorizados. Os (as) autores (as) preservam os direitos autorais, mas não têm permissão para a publicação da contribuição em outro meio, impresso ou digital, em português ou em tradução. 